\title{
Antioxidants enzyme activity in Brassica oleracea var. acephala under Cadmium stress
}

\author{
Kanita Šabanović1 , Ahmet Yildirim ${ }^{2}$, Jasmin Šutković ${ }^{3 *}$ \\ ${ }^{1,2,3}$ Genetic and Bioengineering, International University of Sarajevo (IUS)
}

*Corresponding author: jsutkovic@ ius.edu.ba

(C) The Author

2020.

Published by

ARDA.

\begin{abstract}
When a plant is under heavy metals stress, it has different mechanism of coping with it. Brassica oleracea var. acephala (kale) is a plant that has an ability of heavy metal accumulation and removal of heavy metals from the ground. The plants were exposed to $50,100,200$, and $500 \mu \mathrm{M}$ of $\mathrm{CdCl}_{2}$ for 5 days, in controlled in vitro conditions. Root length was measured to confirm the $\mathrm{Cd}$ effect on plant growth. There are five key antioxidants enzymes responsible for the regulation of heavy metals stress: superoxide dismutase (SOD), catalase (CAT), ascorbate peroxidase (APX), Peroxidase (POD) and Polyphenol oxidase (PPO). All enzymes showed significant activity, especially triggered by $500 \mu \mathrm{M} \mathrm{CdCl}_{2}$ in both varieties. The domestic sorts seem more resistant if compared to hybrid variety, showing significant lower expression of antioxidants enzymes at higher concentrations. In general, significant percentage of enzymes is more expressed in the hybrid Italian sort, Nero di Toscana, indicating the ability of domestic sorts to be more resistant to heavy metal stress.
\end{abstract}

Keywords: heavy metals, Brassica oleracea, Antioxidant enzymes, Superoxide Dismutase

\section{Introduction}

The periodic system of elements contains 90 natural elements. Of those 90,53 are classified as heavy metals [1]. Some metals are micronutrients - meaning they are essential to human in small doses, but some, such a $\mathrm{Pb}, \mathrm{As}, \mathrm{Hg}$ and $\mathrm{Cd}$ are nonessential and toxic to human. However, there is no widely accepted definition of heavy metals, but they are considered as elements that has a density more than $5 \mathrm{~g} / \mathrm{mp}^{3}$ [2].

Out of all heavy metals - Cadmium is one of the most toxic one. It is a non-essential element that can appear it the nature both naturally and by anthropogenic factor [3,4]. Human can be exposed to cadmium trough food, water, as well as tobacco, drugs, cosmetics or dietary supplements [5-7]. Main foods through which cadmium is ingested into the body are the vegetables and cereals but can also be through animals - kidney and liver since they accumulate cadmium. Through creating oxidative stress, cadmium is inducing tissue injury, epigenetic changes, inhibiting or upregulating different transport pathways, inhibition of heme synthesis [5-8]. Cadmium and his compounds are, according to International Agency for Research on Cancer (IARC) classified as Group 1 - meaning "carcinogenic to humans". According to IARC there is enough evidence that cadmium contributes to development of lung cancer, and limited evidence for development of prostate and kidney cancer [9].

The major site for cadmium accumulation in the body are the kidneys [10], and it is associated with kidney cancer [11]. It also affects the gut microbiota, the abundance, and its relative population. In the intestinal walls it induces cell damage and inflammatory response [12]. Cadmium can also accumulate in the endometrium. 
Thus, it is a potential causative of estrogen-diseases, such as endometrial or breast cancer, spontaneous abortions, and endometriosis. Higher intake of cadmium is related to higher endometrial cancer risk. In the endometrial cells they play an important role in placentation, embryogenesis and implantation [13]. Cadmium exposure can affect the sperm quality, penetration into oocytes and the embryo development of one derived from natural fertilization [14].

It also affects female reproduction, balance of reproductive hormones and menstrual cycles. Furthermore, during pregnancy, cadmium exposure affects female offspring more than male [15].

The main source of cadmium in foods is coming from plants [4]. It is causing phytotoxicity and by this becoming a threat for both human and animal trough food chains. It is highly mobile in water-soil-plant system since it is more soluble in water than other metals [16].

According to the World Health Organization, The Joint Food and Agriculture Organization of the United Nations (FAO)/WHO Expert Committee on Food Additives (JECFA) the - provisional tolerable monthly intake (PTMI) is $25 \mu \mathrm{g} / \mathrm{kg}$ body weight. Cadmium has a long biological half-life and is a toxicant that is cumulative [6]. It has a half-life of 25 years, representing depositions in the organs, not removal from the body [5]. It takes decades for cadmium to be removed from the tissues and organs from the body [17], and is mainly removed with fecal and urinary excretion [8]

The presence of cadmium induced the inhibition of growth, oxidative damage, and genotoxicity in the seedlings, increasing the activities of antioxidant enzymes and proline accumulation as well as limiting the uptake of potassium (K) and calcium (Ca) [18]. Furthermore, it causes oxidative stress, inhibition of enzymes and inactivation of biomolecules [19].

Plant can resist to heavy metal stress by avoiding it, meaning being protected externally, and by tolerating it, meaning coping with the stress internally [20]. There are different mechanisms to prevent the entry in the roots, such as thick cuticle, cell walls, trichomes. If the heavy metals, despite the biophysical barriers, enter the plant, the plant will start to synthesize various biomolecules. Those include biomolecules such as chelators or metallochaperones and cellular exudates or metallothioneins. If these, above mentioned mechanisms, are not able to resist the heavy metal contamination, there will be an increase of reactive oxygen species (ROS) [21].

Free radicals are molecules that can exist independently and contains one or more unpaired electrons alone in an electron orbital. The oxidative metabolism is producing free radicals that are oxygen-centered, as well as other reactive oxygen species (ROS) [22]. In plants, ROS can cause DNA damage, unspecific oxidation of membrane lipids and proteins, enzyme inhibition by activation of apoptosis [19].

However, since ROS are playing an important role of the plant defense system, it cannot be totally omitted from the plant. ROS will begin to be harmful when the concentration exceeds the threshold for defense mechanisms [19] and cause oxidative stress [23]. In normal conditions, plants have a mechanism to cope with ROS. But under stress, the production on ROS is increased as the cell homeostasis is disrupted. For a plant to cope with this kind of disorder, the antioxidative mechanisms are activated [24]. An antioxidant is a stable molecule that is donating an electron to the free radical and thus, neutralizing it. By neutralizing the free radicals, the antioxidant is reducing its ability to cause a damage. There are different enzymatic and nonenzymatic antioxidants, which can be found in the diet, or produced by the body metabolism [25]. Nonenzymatic are ones such as glutathione, vitamin C, vitamin E; and enzymatic antioxidant are ones such as peroxidase (POD), catalase (CAT), ascorbate [25], superoxide dismutase (SOD) [22], polyphenol oxidase (POD) [26], ascorbate peroxidases (APX) [27] etc. Levels of ROS-cleaning enzymes or antioxidants are in part determining the ability of a plant to tolerate different environmental stresses [28].

Superoxide dismutase (SOD) is one of the most important enzymes that is enabling organism to cope with the presence of molecular oxygen [23]. It is the first enzyme to detoxicate the ROS generated. [29]. Catalyze (CAT) is an enzyme which is found in almost all living organisms. It is reducing hydrogen peroxide, a harmful byproduct of normal metabolic processes, to hydrogen and water [25]. By removing the hydrogen peroxide, CAT is preserving cell walls from membrane damage and lipid production. [29]. Polyphenol Oxidase (PPO) can be found in fungi, plants, humans, as well as in some higher animals. It is also present in higher plants where it protects the plants against microorganisms and insects [30]. The generation of $o$ quinone which is mediated by PPO is also connected with generation of ROS (as a secondary reaction product) [31]. Peroxidases are present in plants, animals, and microorganisms. In plants, they are responsible for various functions, such as general stress response, rigidification, wound healing (which appears after stress which will induce POX formation), lignification, suberization, construction, strengthening the cell walls, defense against pathogens or protecting the tissues against physical damage. [32,33]. 
Ascorbate Peroxidase (APX) is a key enzyme responsible for the removal of excess hydrogen peroxide under both stress and normal conditions. [34]. It is responsible for reduction of hydrogen peroxide to water and monodehydroascorbate, using ascorbate as a substrate [35].

The genus Brassica is including a vast variety of more than 30 species, with different varieties and hybrids. Brassica vegetables contains glucosinolate, polyphenol, carotenoid, provitamin A, Vitamin C, K, B9 and B2, Calcium, [36], as well as some antioxidant enzymes, CAT, POX and SOD [37].

Brassica oleracea varieties include variety of vegetables that human is using for consumption, such as broccoli, cauliflower, cabbages, Brussel sprouts and others. They are used as a food, oil production, animal fodder and others [38]. Among the Brassica vegetables, Brassica oleracea var. acephala (kale) has more calcium, vitamin C, K, A, B2 B9 content that the others [39].

The Brassica vegetables have beneficial properties such as anticarcinogenic properties, protecting against cardiovascular diseases, protecting against ageing processes, etc. Some Brassica species has been found out to be good heavy metal accumulators, and thus, used in phytoremediation process. [40]. They have the ability to accumulate heavy metals in the parts above the ground, tolerance to the high concentration of heavy metals in the soils, rapidly grow and highly accumulating biomass and they are easy to harvest and to grow as an agricultural crop [2,38].

The aim of this study is to examine different sorts of Brassica oleracea var. acephala for their enzymatic activity in kales of domestic and hybrid origins.

\section{Materials and methods}

\subsection{Seed germination and root analysis}

The seeds that were used was a hybrid variety kale NT (Nero di Toscana, an Italian sort) and a domestic variety sort from Stolac (village Ravine) from the region of Herzegovina.

The seeds were germinated using the tap and paper method [41]. Two layers of paper tissues were placed in each petri dishes $(9 \mathrm{~cm}$ diameter). Each petri dish was moistened with different concentration of cadmiumchloride (Table 1). The stock solutions were prepared from cadmium-chloride $\left(\mathrm{CdCl}_{2}\right)$ from Sigma-Aldrich and distilled water. Thirty seeds were placed in each petri dish. Each petri dish contained seeds with different concentrations of $\mathrm{CdCl}_{2}$.

Table $1 . \mathrm{CdCl}_{2}$ concentrations

\begin{tabular}{|l|l|l|l|l|l|}
\hline Petri-dish & 1 & 2 & 3 & 4 & 5 \\
\hline Concentration & $0 \mu \mathrm{M}($ Control $)$ & $50 \mu \mathrm{M}$ & $100 \mu \mathrm{M}$ & $200 \mu \mathrm{M}$ & $500 \mu \mathrm{M}$ \\
\hline
\end{tabular}

The petri-dishes were then placed in a Growth Chamber for 5 days, at the temperature of $27^{\circ} \mathrm{C}$ with 16 hours of light per day. After 5 days the seeds were collected, roots were measured for each plant using a ruler. The plants from each petri dish where placed in separate tubes (i.e., concentration) were stored at $-80^{\circ} \mathrm{C}$ fridge, until it is needed for further experiments.

\subsection{Plant tissue extraction for enzyme activity determination}

Extraction buffer of $100 \mathrm{mM}$ phosphate $(\mathrm{pH}=7)$ is made. The root tissues from plants were placed in a mortal and grounded under the liquid nitrogen using a pestle. Weight of $0.3-1.0 \mathrm{~g}$ of obtained plant powder is transferred to the $1.5 \mathrm{~mL}$ Eppendorf tube, and triple amount of phosphate buffer of the plant powder of is added. Stir. The tubes are transferred to the centrifuge and centrifuged at $13.000 \mathrm{x} g$ for 20 minutes and at $4^{\circ} \mathrm{C}$. After the centrifugation, the supernatant is carefully taken with the pipette and transferred to new Eppendorf tubes [42]. 


\subsection{Enzymes activity determination assays}

\subsubsection{Peroxidase (POX) activity determination assay}

A $3 \mathrm{~mL}$ of $0.1 \mathrm{M}$ phosphate buffer $(\mathrm{pH}=6.5)$ was added to the tube. Then, $100 \mu \mathrm{L}$ of $20 \mathrm{mM}$ guaiacol (prepared under the hub) and $100 \mu \mathrm{L}$ of enzyme was added. To initiate the reaction, $30 \mu \mathrm{L}$ of $12 \mathrm{mM}$ hydrogen peroxide was added. The process is repeated for each obtained enzyme (i.e., each petri dish). Control group is made, with the hereby reaction mixture, but without the enzyme. A $200 \mu \mathrm{L}$ from each tube and place it in each well of the 96-well plate. Measure the absorbance at $436 \mathrm{~nm}$ at $0 \mathrm{~min}$ and $2 \mathrm{~min}$ [43].

Peroxidase is catalyzing the hydrogen removal from large number of molecules, as well as decomposition of hydrogen peroxide. POX will bind hydrogen peroxide and the complex obtained, [POD-H2O2], can oxidize different hydrogen donors. By formation of an oxidized compound, among other methods, the activity of POX can be determined. Guaiacol is a non-cancerogenic substrate, which acts as a substrate for POX, where one mole of guaiacol is oxidized by one mole of hydrogen peroxide. The end product of this reaction is tetraguaiacol which is measured spectrophotometrically at $436 \mathrm{~nm}$ [43-45].

In the experiment performed, guaiacol and enzyme source are firstly added, where the guaiacol acts as a substrate. For reaction to start, hydrogen peroxide was added, and as a result tetraguaiacol was formed. Thus, it is expected that the absorption is increasing, with the increasing concentration of cadmium (more cadmium, more POX, more tetraguaiacol).

\subsubsection{Superoxide dismutase (SOD) activity determination assay}

A $1.3 \mathrm{~mL}$ of $50 \mathrm{mM}$ of sodium carbonate buffer is added to the test tube. Then, $500 \mu \mathrm{L}$ of $96 \mathrm{mM}$ Nitroblue tetrazolium (NBT) $(\mathrm{pH}=10.0)$ and $100 \mu \mathrm{L}$ of $0.6 \%$ Triton X-100 was added. To initiate the reaction, $100 \mu \mathrm{L}$ of $20 \mathrm{mM}$ hydroxylamine hydrochloride $\left(\mathrm{NH}_{2} \mathrm{OH} . \mathrm{HCl}\right)(\mathrm{pH}=6.0)$ was added. A $70 \mu \mathrm{L}$ of enzyme is added. The process is repeated for each obtained enzyme (i.e., each petri dish). Control group is made, with the hereby reaction mixture, but without the enzyme. A $200 \mu \mathrm{L}$ from each tube and place it in each well of the 96well plate. Measure the absorbance at $540 \mathrm{~nm}$ at $0 \mathrm{~min}$ and $2 \mathrm{~min}$ [46].

Hydroxylamine will autoxidize and generate superoxide radicals. NBT, which is colorless, will be reduced by superoxide radicals, and turn NBT to blue formazan, which can be measured spectrophotometrically. The SOD, which is scavenging the superoxide radicals is going to inhibit the blue color formation. Thus, as more SOD is present, less color will appear [46, 47].

\subsubsection{Polyphenol oxidase (PPO) activity determination assay}

A $1.5 \mathrm{~mL}$ of $50 \mathrm{mM}$ phosphate buffer $(\mathrm{pH}=6.5)$ was added to the tube. Then, $200 \mu \mathrm{L}$ of the enzyme is added. To initiate the reaction, $200 \mu \mathrm{L}$ of $100 \mathrm{mM}$ catechol was added. The process is repeated for each obtained enzyme (i.e., each petri dish). Control group is made, with the hereby reaction mixture, but without the enzyme. A $200 \mu \mathrm{L}$ from each tube and place it in each well of the 96-well plate. Measure the absorbance at $495 \mathrm{~nm}$ at 0 min and $2 \mathrm{~min}$ [48].

For Polyphenol Oxidase, catechol is used as a substrate, which will, in the present of oxygen form quinone. The amount of quinone is measured spectrophotometrically. Thus, as more PPO is present, more quinone is generated [49].

\subsubsection{Catalase (CAT) activity determination assay}

A $1.9 \mathrm{ml}$ of $50 \mathrm{mM} \mathrm{PBH}(\mathrm{pH}=7.0)$ was added to the tube. Then, $0.1 \mathrm{ml}$ of the enzyme was added. To initiate the reaction, $1.0 \mathrm{~mL}$ of $0.075 \% \mathrm{mM}$ hydrogen peroxide was added. The process is repeated for each obtained enzyme (i.e., each petri dish). Control group is made, with the hereby reaction mixture, but without the enzyme. A $200 \mu \mathrm{L}$ from each tube and place it in each well of the 96-well plate. Measure the absorbance at $240 \mathrm{~nm}$ at $0 \mathrm{~min}$ and $2 \mathrm{~min}$ [50].

Catalase is decomposing hydrogen peroxide to water and oxygen. The decomposition of hydrogen peroxide is measured at $240 \mathrm{~nm}$ [50]. Thus, as more CAT is present, less hydrogen peroxide will be present, as the catalase will decompose the hydrogen peroxide. 


\subsubsection{Ascorbate peroxidase (APX) activity determination assay}

A $1.5 \mathrm{ml}$ of $100 \mathrm{mM}$ phosphate buffer $(\mathrm{pH}=7.0)$ is added to the tube. Then, $300 \mu \mathrm{L}$ of $5 \mathrm{mM}$ ascorbate, and $600 \mu \mathrm{L}$ of enzyme is added to each tube. To initiate the reaction, $0.5 \mathrm{mM}$ of $600 \mu \mathrm{L}$ of hydrogen peroxide is added. The process is repeated for each obtained enzyme (i.e., each petri dish). Control group is made, with the hereby reaction mixture, but without the enzyme. A $200 \mu \mathrm{L}$ from each tube and place it in each well of the 96-well plate. Measure the absorbance at $290 \mathrm{~nm}$ at $0 \mathrm{~min}$ and $2 \mathrm{~min}$ [51].

Ascorbate Peroxidase is an enzyme that scavenge hydrogen peroxide, using ascorbate as an electron donor, which will oxidase. The amount of ascorbate is measured spectrophotometrically [52]. As more APX is present, less ascorbate will be available.

\section{Results}

\subsection{Root measurements}

\section{Avarage Root Length}

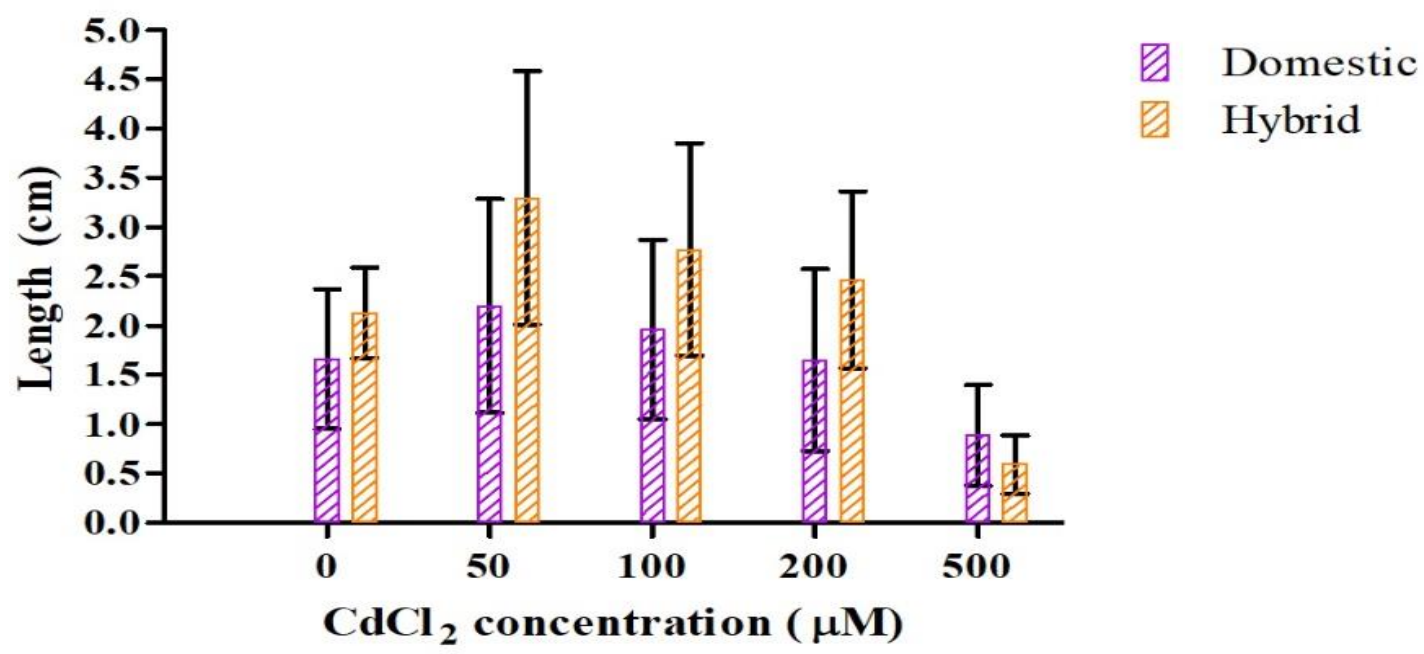

Figure 1. Average root length in domestic and hybrid sorts; with standard deviation

From the Fig. 1 it can be observed that the hybrid sorts have larger roots for all $\mathrm{CdCl}_{2}$ concentrations, except for $500 \mu \mathrm{M}$. The root length decreases with the increase of $\mathrm{CdCl}_{2}$ concentration, except for control group in both domestic and hybrid sorts. The root length was largest for the concentration of $50 \mu \mathrm{M}$, while the root length was smallest for the concentration of $500 \mu \mathrm{M}$, for both domestic and hybrid sorts. Also, root length is decreasing for both domestic and hybrid sorts, from the concentration of $50 \mu \mathrm{M}$.

In table 2. descriptive analysis of domestic and hybrid root lengths. The $p$-value $(\mathrm{T}<=\mathrm{t})$ for both one-tail and two tail are greater than 0,05 , which represent insignificant difference.

Table 2. T-Test: two-sample assuming equal variances; Domestic VS. Hybrids root length

\begin{tabular}{|c|c|c|}
\hline & Average of $2 \mathrm{~min}-$ domestic & Average of 2 min - hybrid \\
\hline Mean & 1,67362258 & 2,25177 \\
\hline Variance & 0,245413288 & 1,045952791 \\
\hline t Stat & & $-1,137048672$ \\
\hline $\mathbf{P}(\mathbf{T}<=$ t) one-tail & 0,144213248 \\
\hline $\mathbf{t}$ Critical one-tail & 1,859548038 \\
\hline $\mathbf{P}(\mathbf{T}<=$ t) two-tail & 0,288426495 \\
\hline $\mathbf{t}$ Critical two-tail & 2,306004135 \\
\hline
\end{tabular}




\subsection{Enzyme activity}

\subsubsection{Peroxidase (POX) Activity}
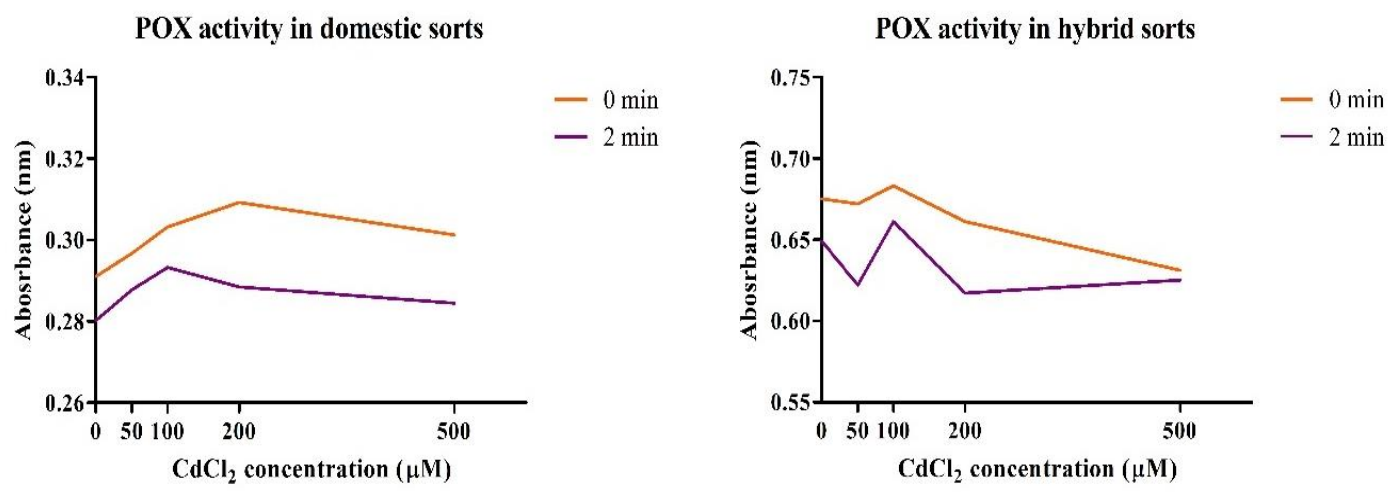

Figure 3.POX activity in domestic and hybrid sorts

In Fig . 3 we show that the first control group $(0 \mathrm{Cd})$, the values at 0 min and 2 min for domestic sort was 0,036 for domestic sort and 0,051 for hybrid sort. Since no enzyme is present (POX) the reaction is not catalyzed. The activity of POX enzyme is larger in the hybrid sort, whereas in the domestic, it is 2 to 3 times smaller. For both sorts, POX activity is decreasing over time. In the domestic sort, POX activity at both 0 min and $2 \mathrm{~min}$ is smallest for the second control group and is greatest at the concentration of 200 at 0 min, and 100 $\mu \mathrm{M}$ at $2 \mathrm{~min}$; after which activity of POX activity is increasing. For the hybrid sort, POX activity is smallest at $500 \mu \mathrm{M}$ for $0 \mathrm{~min}$ and $200 \mu \mathrm{M}$ for $2 \mathrm{~min}$ and is largest at 100 for both 0 min and 2 min.

In Table 3. descriptive analysis of domestic and hybrid for POX activity is shown. The $\mathrm{p}$-value $(\mathrm{T}<=\mathrm{t})$ for both one-tail and two tail are less than 0,05 , which represent significant difference.

Table 3.T-Test: Domestic VS. Hybrids - POX enzyme activity (absorbance)

\begin{tabular}{|c|c|c|}
\hline & Average of 2 min - domestic & Average of 2 min - hybrid \\
\hline Mean & 0,2885 & 0,63125 \\
\hline Variance & 0,000013041666 & 0,000404 \\
\hline $\mathbf{t}$ Stat & \multicolumn{2}{|c|}{$-33,5573458$} \\
\hline $\mathbf{P}(\mathbf{T}<=\mathbf{t})$ one-tail & 0,0000000023 \\
\hline $\mathbf{t}$ Critical one-tail & 1,943180281 \\
\hline $\mathbf{P}(\mathbf{T}<=t)$ two-tail & 0,0000000466 \\
\hline t Critical two-tail & 2,4469118511 \\
\hline
\end{tabular}

\subsubsection{Superoxide Dismutase (SOD) Activity}

SOD activity in domestic sorts

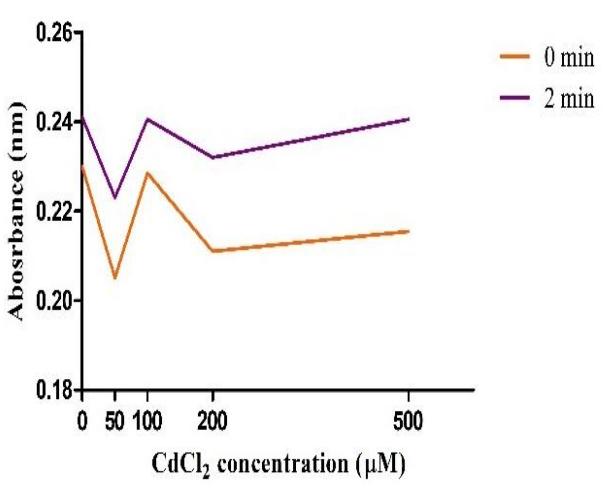

SOD activity in hybrid sorts

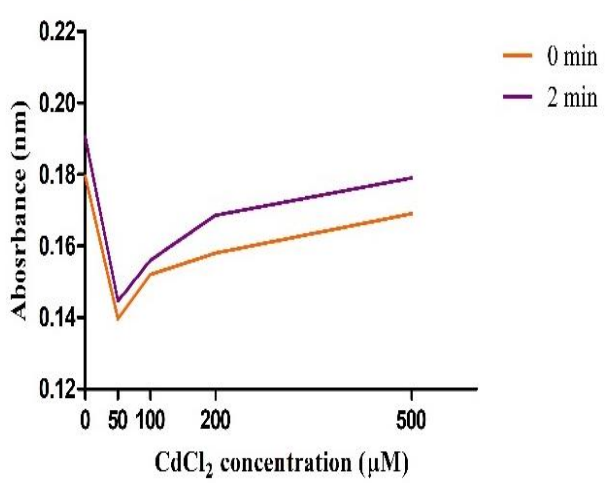

Figure 4. SOD activity in domestic and hybrid sorts 
In Fig. 4 we see that the control group the absorption for domestic sort was 0,44 and 0,47 at 0 min and $2 \mathrm{~min}$ respectively, while for the hybrid sort the absorption was at both 0,51 for $0 \mathrm{~min}$ and $2 \mathrm{~min}$, which is a mistake due to wrong pipetting. The absorption was the smallest for both domestic and hybrid sort. In domestic sort the SOD levels are fluctuating, rising from control to $50 \mu \mathrm{M}$, decreasing from $50 \mu \mathrm{M}$ to $100 \mu \mathrm{M}$, again rising to $200 \mu \mathrm{M}$, and finally decreasing from $200 \mu \mathrm{M}$. In hybrids, SOD levels are increasing until the concentration of $50 \mu \mathrm{M}$, after which its levels are decreasing.

In Table 4, descriptive analysis of domestic and hybrid for SOD activity is shown. The $p$-value $(\mathrm{T}<=\mathrm{t})$ for both one-tail and two tail are less than 0,05 , which represent significant difference.

Table 4. T-Test: Domestic VS. Hybrids - SOD enzyme activity (absorbance)

\begin{tabular}{|l|c|c|}
\hline & Average of 2 min - domestic & Average of 2 min - hybrid \\
\hline Mean & 0,234 & 0,162 \\
\hline Variance & 0,0000698333333333332 & 0.0002245 \\
\hline t Stat & \multicolumn{2}{|c|}{8,39349367825105} \\
\hline P $(\mathbf{T}<=t)$ one-tail & 0,00007786530296291 \\
\hline t Critical one-tail & \multicolumn{2}{|c|}{1,9431802805153} \\
\hline P $(\mathbf{T}<=t)$ two-tail & 0,00015573060592582 \\
\hline t Critical two-tail & 2,44691185114497 \\
\hline
\end{tabular}

\subsubsection{Polyphenol Oxidase (PPO) Activity}

PPO activity in domestic sorts

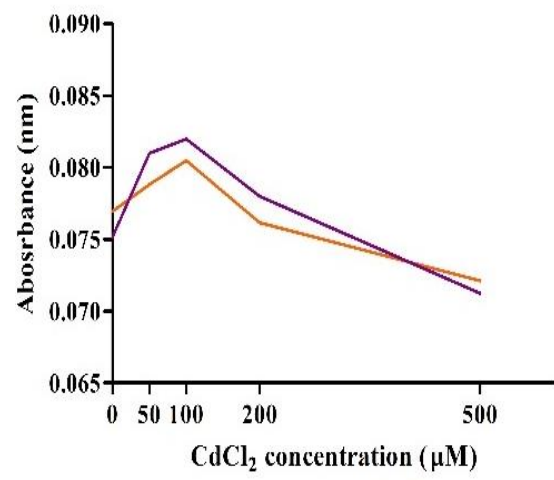

PPO activity in hybrid sorts

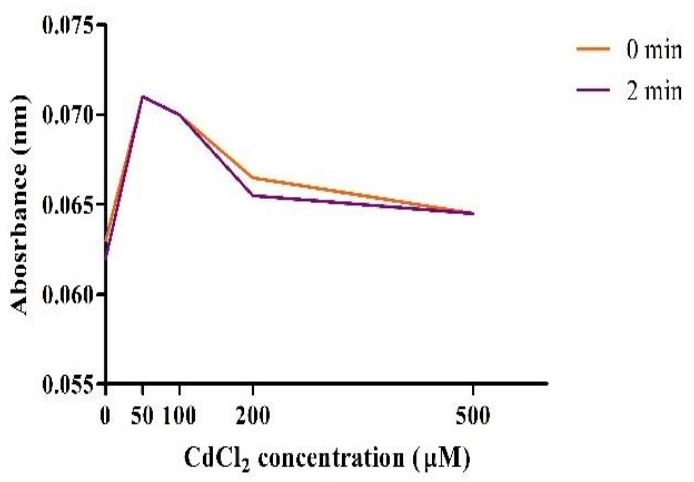

Figure 5. PPO activity in domestic and hybrid sorts

In the first control group the absorption for both domestic and hybrid at $0 \mathrm{~min}$ and $2 \mathrm{~min}$ were $0,05( \pm 0,005)$. The highest vales for domestic sorts were at concentration of $100 \mu \mathrm{M}$, and at $50 \mu \mathrm{M}$ for hybrid sorts, after which the absorption decreases, for both $0 \mathrm{~min}$ and $2 \mathrm{~min}$. The lowest values, omitting control groups, were at the concentration of $500 \mu \mathrm{M}$.

In table 5. descriptive analysis of domestic and hybrid for PPO activity is shown. The $p$-value $(\mathrm{T}<=\mathrm{t})$ for both one-tail and two tail are less than 0,05 , which represent significant difference.

Table 5. T-Test: Domestic VS. Hybrids - PPO enzyme activity (absorbance)

\begin{tabular}{|l|c|c|}
\hline & Average of 2 min - domestic & Average of 2 min - hybrid \\
\hline Mean & 0,0780625 & 0,06775 \\
\hline Variance & 0,000023515625 & 0,00001041666 \\
\hline $\mathbf{t}$ Stat & & 3,540685574 \\
\hline $\mathbf{P}(\mathbf{T}<=\mathbf{t})$ one-tail & \multicolumn{3}{|c|}{0,006104385} \\
\hline $\mathbf{t}$ Critical one-tail & \multicolumn{3}{|c|}{1,943180281} \\
\hline $\mathbf{P}(\mathbf{T}<=\mathbf{t})$ two-tail & \multicolumn{3}{|c|}{0,002208771} \\
\hline $\mathbf{t}$ Critical two-tail & 2,446911851 \\
\hline
\end{tabular}




\subsubsection{CAT activity}

CAT activity in domestic sorts

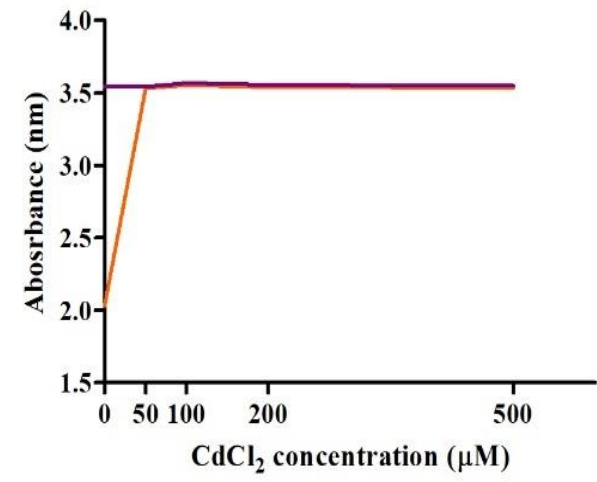

CAT activity in hybrid sorts

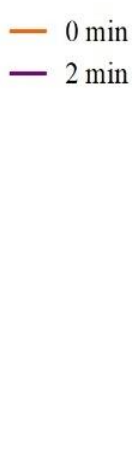

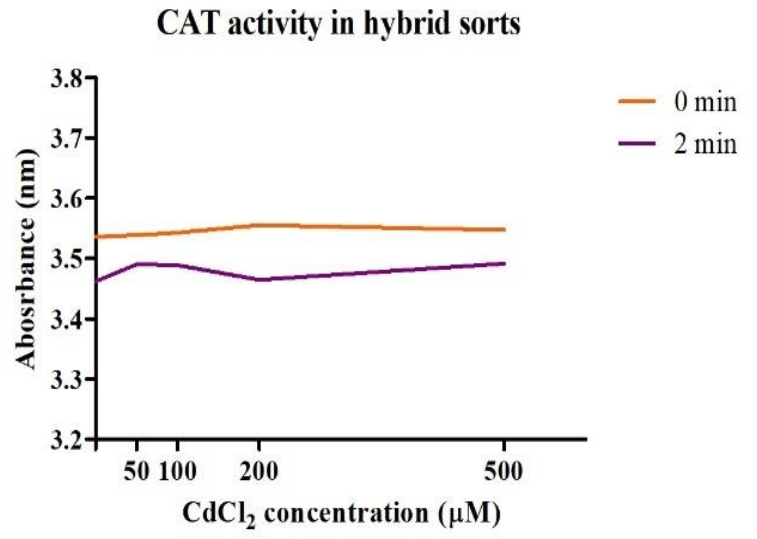

Figure 6. CAT activity in domestic and hybrid sorts

In the first control group the absorption for both domestic and hybrid at 0 min and 2 min were 3,45 $( \pm 0,005)$. The CAT activity did not change through time and remained almost the same with the change of $\mathrm{Cd}$ concentration for the domestic sort. For the hybrid sort, the absorption decreased through time, indicating more CAT utilization; but remained relatively stable through time. Furthermore, in hybrid, at 0 min, CAT levels were slightly increasing for $0 \mathrm{~min}$, and slightly decreasing for $2 \mathrm{~min}$.

In table 6. descriptive analysis of domestic and hybrid for CAT activity is shown. The p-value $(\mathrm{T}<=\mathrm{t})$ for both one-tail and two tail are less than 0,05 , which represent significant difference.

Table 6. T-Test: Domestic VS. Hybrids - CAT enzyme activity (absorbance)

\begin{tabular}{|l|c|c|}
\hline & Average of 2 min - domestic & Average of 2 min - hybrid \\
\hline Mean & 3,5548125 & 3,4835 \\
\hline Variance & 0,00009714 & 0,00016 \\
\hline $\mathbf{t}$ Stat & \multicolumn{2}{|c|}{0,8598814} \\
\hline $\mathbf{P}(\mathbf{T}<=\mathbf{t})$ one-tail & \multicolumn{2}{|c|}{0,000057498957} \\
\hline $\mathbf{t}$ Critical one-tail & \multicolumn{2}{|c|}{0,9431803} \\
\hline $\mathbf{P}(\mathbf{T}<=\mathbf{t})$ two-tail & 2,000115 \\
\hline$t$ Critical two-tail & \multicolumn{2}{|c|}{2,4469119} \\
\hline
\end{tabular}

\subsubsection{Ascorbate peroxidase (APX) activity}

APX activity in domestic sorts

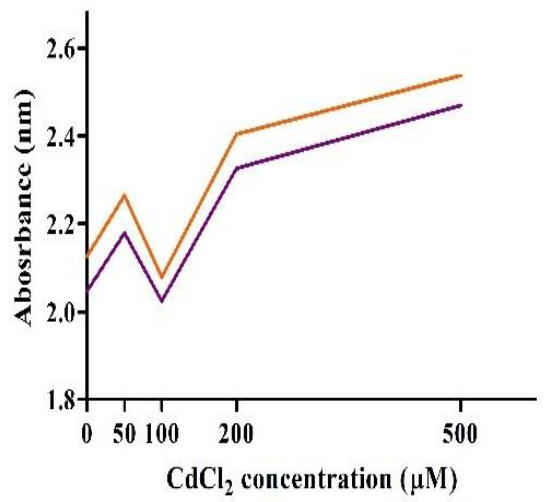

APX activity in hybrid sorts

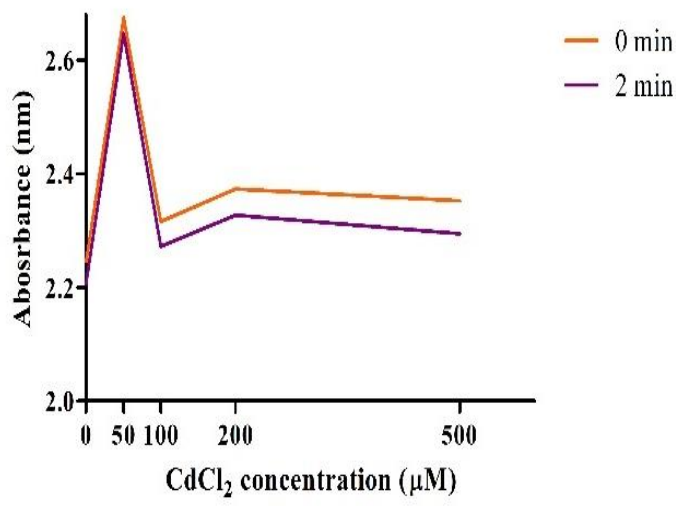

Figure 7. APX activity in domestic and hybrid sorts 
The values for the first control groups were 2,53 and 2,65 at both 0 min and 2 min, for domestic and hybrid sort, respectively. The amount of APX through time is increasing, for both domestic and hybrid sorts. The amount of APX throughout different concentrations is fluctuating. In domestic sort, the highest values of APX were at $100 \mu \mathrm{M}$ at both $0 \mathrm{~min}$ and $2 \mathrm{~min}$, after which the amount of APX is decreasing. In hybrid sort the highest values were at control group and $100 \mu \mathrm{M}$ at $2 \mathrm{~min}$ and $0 \mathrm{~min}$, respectively. After concentration of 100 $\mu \mathrm{M}$, the amount of APX is also decreased, but is again rising after $200 \mu \mathrm{M}$.

In table 7. descriptive analysis of domestic and hybrid for APX activity was done. The $\mathrm{p}$-value $(\mathrm{T}<=\mathrm{t})$ for both one-tail and two tail are greater than 0,05 , which represent insignificant difference.

Table 7. t-Test: Domestic VS. Hybrids - APX enzyme activity (absorbance)

\begin{tabular}{|l|c|c|}
\hline & Average of 2 min - domestic & Average of $\mathbf{2}$ min - hybrid \\
\hline Mean & 2,24981 & 2,38538 \\
\hline Variance & 0,03663 & 0,03093 \\
\hline T Stat & & $-1,04309$ \\
\hline $\mathbf{P}(\mathbf{T}<=$ One Tail) & $\mathbf{0 , 1 6 8 5 5}$ \\
\hline $\mathbf{T}$ Critical One-Tail & 1,94318 \\
\hline $\mathbf{P}(\mathbf{T}<=\mathbf{T})$ Two-Tail & $\mathbf{0 , 3 3 7 1}$ \\
\hline $\mathbf{T}$ Critical Two-Tail & 2,44691 \\
\hline
\end{tabular}

\section{Discussion}

The aim of this study was to examine the enzyme activity of domestic and hybrid sorts of Brassica oleracea var. acephala under cadmium stress. The damage can be repaired by antioxidants, which can be nonenzymatic and enzymatic. The presence of heavy metals cause $\mathrm{H}_{2} \mathrm{O}_{2}$ production, which will increase the level of oxidative enzymes [25].

Since the root is in direct contact with the heavy metal, they are affected more than other parts [38]. This study showed that the root length was highest for the concentration of $50 \mu \mathrm{M}$, followed by $100, \mu \mathrm{M}, 0 \mu \mathrm{M}$ (control), $200 \mu \mathrm{M}$ and $500 \mu \mathrm{M}$. [38]. In the study conducted by Meng et al.,2009, the root length was higher at small concentrations $(10 \mu \mathrm{M}$ of $\mathrm{Cd})$, positively affecting it [53].

According to them, the Cd was transported to shoots, which can explain this phenomenon. Also, a similar study explained this phenomenon as the disruption of the homeostasis occur, which will lead to overcompensation response [38].

The CAT activity for domestic kale was rising until the concentration of $100 \mu \mathrm{M}$, at both 0 min and $2 \mathrm{~min}$, after which it started to decrease. These results are in consistence with the study of Taylor et al., 2013 [54], which showed that the CAT levels were rising until the concentration of $100 \mu \mathrm{M} \mathrm{CdCl}_{2}$ in Brassica juncea. However, for the hybrid sort, the CAT levels decreased after the concentration of $200 \mu \mathrm{M}$ and $50 \mu \mathrm{M}$ at $0 \mathrm{~min}$ and $2 \mathrm{~min}$, respectively.

The levels or SOD in our study were rising, decreasing, rising, and decreasing in domestic, while in hybrid it was rising, and then decreasing. For POX, its levels were rising, and then dropping after concentration of 100 $\mu \mathrm{M}$ for domestic, and for hybrid rising and dropping, after the concentration of $50 \mu \mathrm{M}$. In the study conducted by Zhang et al., 2019 which was conducted on Brassica juncea L. (Indian mustard) and Medicago sativa L. (alfalfa), the SOD levels were increasing until the concentration of $150 \mathrm{mg} / \mathrm{kg}$ of Cd, after which the levels of that enzyme were dropping until the final concentration of $600 \mathrm{mg} / \mathrm{kg}$ [55]. For POX, the levels dropped until the concentration of $75 \mathrm{mg} / \mathrm{kg}$ of $\mathrm{Cd}$.

In this study, the CAT activity was also examined, in which its levels were rising until $150 \mathrm{mg} / \mathrm{kg}$, and then dropping. According to them, the rising and dropping levels of SOD and POD enzymes is a usual defense mechanism that plants have against stress caused by Cd. The CAT levels also remained relatively stable for different concentrations in Indian Mustard, with levels decreasing from the concentration of $100 \mu \mathrm{M}$. The trend of decreasing of CAT may be because CAT is most sensitive to heavy metal stress, which activity is firstly inhibited, which will result in $\mathrm{H}_{2} \mathrm{O}_{2}$ clearance obstruction, so that the superoxide can be only removed by the POD enzyme, and thus POD levels are increased. But with the Cd levels being increased, the 
accumulation of ROS results in membrane lipid peroxidation, which is also increased, and thus POD will finally decrease.

The APX level were fluctuating, but the final increase of APX was recorded at the concentration after $100 \mu \mathrm{M}$ for hybrid, and final decrease after $100 \mu \mathrm{M}$ for domestic. A study conducted by Mobin \& Khan, 2007of Varuna cultivar of Brassica juncea L., the APX levels were also increasing with the Cd increasing [56]. However, there is a threshold, a sub-lethal concentration, which induced maximum level of APX, after which the APX levels are decreasing. The APX, together with SOD is one of the key enzymes in $\mathrm{H}_{2} \mathrm{O}_{2}$ scavenging. The APX levels were higher in plants that are known as metal accumulators, such as Brassica juncea, Sedum alfredii, Triticum aestivum, as the upregulation of APX increases the ability to overcome Cd stress [57]. Furthermore, Armas et al., 2015 stated that in B. juncea, APX and CAT are not competing, but rather different enzyme classes that scavenge $\mathrm{H}_{2} \mathrm{O}_{2}$; APX for fine ROS modulation, and APX for excess ROS that accumulated during stress [58].

For PPO enzyme, this study showed that its levels decreased from concentration of $50 \mu \mathrm{M}$ and $100 \mu \mathrm{M}$ for hybrid and domestic sorts, respectively. However, in a study conducted by Kapoor et al., 2014 on Brassica juncea, the PPO levels were fluctuating, as they were rising, decreasing and again rising, with the highest levels at the concentration of $600 \mu \mathrm{M}$ of $\mathrm{Cd}[59]$.

Finally, our study showed that out of 5 enzymes, taking in account samples at 0 min and $2 \mathrm{~min}$, PPO and SOD showed more activity in domestic sorts, as well as POX for $0 \mathrm{~min}$. Furthermore, considering both 0 min and 2 min, $50 \%$ of enzymes showed decrease at $100 \mu \mathrm{M}$, and 30\% of enzymes showed decrease from $200 \mu \mathrm{M}$ for domestic sorts; not considering CAT, which levels were rising. But for hybrid sorts, $66 \%$ present showed decreasing levels of enzymes from the concentration of $50 \mu \mathrm{M}$, and $16 \%$ decreasing levels from the concentration levels of both $100 \mu \mathrm{M}$ and $200 \mu \mathrm{M}$; not considering CAT and APX, which levels were rising. The decreasing effects of enzymes at higher concentrations can be explained in a way that plants start to die at higher concentrations, as it was explained by Hayat et al., 2007, where the plant starts to die at $200 \mu \mathrm{M}$ and $250 \mu \mathrm{M}$. Lastly, for 4 out of $5(80 \%)$ enzymes there was significant difference between the enzyme activity in domestic and hybrid sorts [60].

\section{Conclusion}

Heavy metals that are present in the nature can be accumulated by plants and cause various damaging effects on them. Present of heavy metals cause oxidative stress to occur. However, plants have certain mechanism by which they cope with different stresses that affect them, and among them - heavy metal stress. The most effective way of protection is the initiation of antioxidants proteins, both non-enzymatic and enzymatic. Our study compared domestic and hybrid sorts of Brassica oleracea var. acephala to examine which are more resistant to heavy metal stress by examining their enzyme activity. The conclusion that was made from this study is that $80 \%$ of enzymes showed significant difference between domestic and hybrid sorts, meaning that domestic sorts are more resistant to heavy metal stress. The domestic sorts are slightly more resistant if compared to the hybrids, showing decreased enzyme activities at higher concentrations.

\section{References}

[1] G. N. Mitra, Regulation of Nutrient Uptake by Plants: A Biochemical and Molecular Approach. 2015.

[2] M. Tom, T. D. Fletcher, and D. T. McCarthy, "Heavy metal contamination of vegetables irrigated by Urban stormwater: A matter of time?," PLoS One, vol. 9, no. 11, pp. 1-21, 2014, doi: 10.1371/journal.pone.0112441.

[3] L. Chun juan, Y. Cai xia, L. Yu, Z. Ting ting, W. Shu bo, and S. Shi hua, "Phytotoxicity of cadmium on peroxidation, superoxide dismutase, catalase and peroxidase activities in growing peanut (Arachis hypogaea L.)," African J. Biotechnol., vol. 14, no. 13, pp. 1151-1157, 2015, doi: 10.5897/ajb11.3975.

[4] D. Ci, D. Jiang, T. Dai, Q. Jing, and W. Cao, "Effects of cadmium on plant growth and physiological traits in contrast wheat recombinant inbred lines differing in cadmium tolerance," Chemosphere, vol. 77, no. 11, pp. 1620-1625, 2009, doi: 10.1016/j.chemosphere.2009.08.062.

[5] R. A. Bernhoft, "Cadmium toxicity and treatment," Sci. World J., vol. 2013, 2013, doi: $10.1155 / 2013 / 394652$. 
[6] A. Rani, A. Kumar, A. Lal, and M. Pant, "Cellular mechanisms of cadmium-induced toxicity: A review," Int. J. Environ. Health Res., vol. 24, no. 4, pp. 378-399, 2014, doi: 10.1080/09603123.2013.835032.

[7] S. Borowska and M. M. Brzóska, "Metals in cosmetics: Implications for human health," J. Appl. Toxicol., vol. 35, no. 6, pp. 551-572, 2015, doi: 10.1002/jat.3129.

[8] A. Colic et al., "Human health risk assessment of cadmium from cattle meat and offal in Central Bosnia Canton," Agric. Conspec. Sci., vol. 82, no. 3 Special Issue 2, pp. 315-320, 2017.

[9] K. Straif et al., "A review of human carcinogens--part C: metals, arsenic, dusts, and fibres.," Lancet Oncol., vol. 10, no. 5, pp. 453-454, 2009, doi: 10.1016/s1470-2045(09)70134-2.

[10] H. Yang and Y. Shu, "Cadmium transporters in the kidney and cadmium-induced nephrotoxicity," Int. J. Mol. Sci., vol. 16, no. 1, pp. 1484-1494, 2015, doi: 10.3390/ijms16011484.

[11] D. Il'yasova and G. G. Schwartz, "Cadmium and renal cancer," Toxicol. Appl. Pharmacol., vol. 207, no. 2, pp. 179-186, 2005, doi: 10.1016/j.taap.2004.12.005.

[12] A. A. Tinkov, V. A. Gritsenko, M. G. Skalnaya, S. V. Cherkasov, J. Aaseth, and A. V. Skalny, "Gut as a target for cadmium toxicity," Environ. Pollut., vol. 235, pp. 429-434, 2018, doi: 10.1016/j.envpol.2017.12.114.

[13] P. Rzymski, K. Tomczyk, P. Rzymski, B. Poniedziałek, T. Opala, and M. Wilczak, "Impact of heavy metals on the female reproductive system," Ann. Agric. Environ. Med., vol. 22, no. 2, pp. 259-264, 2015, doi: 10.5604/12321966.1152077.

[14] L. lin Zhao et al., "Reproductive effects of cadmium on sperm function and early embryonic development in vitro," PLoS One, vol. 12, no. 11, pp. 1-12, 2017, doi: 10.1371/journal.pone.0186727.

[15] S. Kumar and A. Sharma, "Cadmium toxicity: Effects on human reproduction and fertility," Rev. Environ. Health, 2019, doi: 10.1515/reveh-2019-0016.

[16] G. Choppala et al., "Cellular Mechanisms in Higher Plants Governing Tolerance to Cadmium Toxicity," CRC. Crit. Rev. Plant Sci., vol. 33, no. 5, pp. 374-391, 2014, doi: 10.1080/07352689.2014.903747.

[17] World Health Organization, "Exposure to cadmium: a major public health concern," Prev. Dis. Through Heal. Environ., pp. 3-6, 2010, [Online]. Available: http://www.who.int/ipcs/features/cadmium.pdf.

[18] Ş. S. Çatav, T. O. Genç, M. K. Oktay, and K. Küçükakyüz, "Cadmium Toxicity in Wheat: Impacts on Element Contents, Antioxidant Enzyme Activities, Oxidative Stress, and Genotoxicity," Bull. Environ. Contam. Toxicol., vol. 104, no. 1, pp. 71-77, 2020, doi: 10.1007/s00128-019-02745-4.

[19] R. Fryzova et al., "Oxidative Stress and Heavy Metals in Plants," Environ. Contam. Toxicol., vol. 238, no. December, pp. 22-28, 2017, doi: 10.1007/398.

[20] M. N. V. Prasad, "Cadmium toxicity and tolerance in vascular plants," Environ. Exp. Bot., vol. 35, no. 4, pp. 525-545, 1995, doi: 10.1016/0098-8472(95)00024-0.

[21] A. R. Memon et al., "Plant Defense Response," Trop. Agric. Res., vol. 25, no. 4, pp. 27-54, 2015, doi: 10.1007/978-94-007-4441-7.

[22] G. N. Sharma, G. Gupta, and P. Sharma, "A Comprehensive Review of Free Radicals, Antioxidants, and Their Relationship with Human Ailments," Crit. Rev. Eukaryot. Gene Expr., vol. 28, no. 2, pp. 139-154, 2018.

[23] E. Woith, F. Stintzing, and M. F. Melzig, "SOD activity and extremophilicity: a screening of various plant species," vol. 72, pp. 490-496, 2017, doi: 10.1691/ph.2017.7493.

[24] M. Mourato, R. Reis, and L. Louro, "Characterization of Plant Antioxidative System in Response to Abiotic Stresses: A Focus on Heavy Metal Toxicity," Adv. Sel. Plant Physiol. Asp., 2012, doi: $10.5772 / 34557$.

[25] V. Lobo, A. Patil, A. Phatak, and N. Chandra, "Free radicals, antioxidants and functional foods: Impact on human health," Pharmacogn. Rev., vol. 4, no. 8, pp. 118-126, 2010, doi: 10.4103/09737847.70902.

[26] S. Chen et al., "Phenolic metabolism and related heavy metal tolerance mechanism in Kandelia Obovata under Cd and Zn stress," Ecotoxicol. Environ. Saf., vol. 169, no. June 2018, pp. 134-143, 2019, doi: 10.1016/j.ecoenv.2018.11.004.

[27] A. Schützendübel et al., "Cadmium-Induced Changes in Antioxidative Systems, Hydrogen Peroxide Content, and Differentiation in Scots Pine Roots," Plant Physiol., vol. 127, no. November, pp. 887898, 2001, doi: 10.1104/pp.010318.1. 
[28] N. Ergün, S. Özçubukçu, M. Kolukirik, and Temizkan, "Effects of temperature - Heavy metal interactions, antioxidant enzyme activity and gene expression in wheat (Triticum aestivum L.) seedlings," Acta Biol. Hung., vol. 65, no. 4, pp. 439-450, 2014, doi: 10.1556/ABiol.65.2014.4.8.

[29] A. Emamverdian, Y. Ding, Y. Xie, and S. Sangari, "Silicon mechanisms to ameliorate heavy metal stress in plants," Biomed Res. Int., vol. 2018, 2018, doi: 10.1155/2018/8492898.

[30] J. R. Whitaker, "Polyphenol oxidase," Nature, vol. 142, no. 3585, p. 121, 1938, doi: 10.1201/9780203742136-24.

[31] T. Boeckx, A. L. Winters, K. J. Webb, and A. H. Kingston-Smith, "Polyphenol oxidase in leaves: Is there any significance to the chloroplastic localization?," J. Exp. Bot., vol. 66, no. 12, pp. 3571-3579, 2015, doi: 10.1093/jxb/erv141.

[32] B. Somtürk, R. Kalın, and N. Özdemir, "Purification of peroxidase from red cabbage (Brassica oleracea var. capitata f. rubra) by affinity chromatography," Appl. Biochem. Biotechnol., vol. 173, no. 7, pp. 1815-1828, 2014, doi: 10.1007/s12010-014-0968-1.

[33] J. Wilkesman, D. Castro, L. M. Contreras, and L. Kurz, "Guaiacol peroxidase zymography for the undergraduate laboratory," Biochem. Mol. Biol. Educ., vol. 42, no. 5, pp. 420-426, 2014, doi: 10.1002/bmb.20809.

[34] J. X. Liu et al., "Isolation, purification and characterization of an ascorbate peroxidase from celery and overexpression of the AgAPX1 gene enhanced ascorbate content and drought tolerance in Arabidopsis," BMC Plant Biol., vol. 19, no. 1, pp. 1-13, 2019, doi: 10.1186/s12870-019-2095-1.

[35] A. Sofo, A. Scopa, M. Nuzzaci, and A. Vitti, "Ascorbate peroxidase and catalase activities and their genetic regulation in plants subjected to drought and salinity stresses," Int. J. Mol. Sci., vol. 16, no. 6, pp. 13561-13578, 2015, doi: 10.3390/ijms160613561.

[36] D. Šamec, B. Urlić, and B. Salopek-Sondi, "Kale (Brassica oleracea var. acephala) as a superfood: Review of the scientific evidence behind the statement," Crit. Rev. Food Sci. Nutr., vol. 59, no. 15, pp. 2411-2422, 2019, doi: 10.1080/10408398.2018.1454400.

[37] J. Kapusta-Duch, A. Kopeć, E. Piatkowska, B. Borczak, and T. Leszczyńska, "The beneficial effects of Brassica vegetables on human health.," Rocz. Państwowego Zakładu Hig., vol. 63, no. 4, pp. 389-395, 2012.

[38] M. P. Mourato, I. N. Moreira, I. Leitão, F. R. Pinto, J. R. Sales, and L. L. Martins, "Effect of heavy metals in plants of the genus Brassica," Int. J. Mol. Sci., vol. 16, no. 8, pp. 17975-17998, 2015, doi: 10.3390/ijms160817975.

[39] B. Bergh and G. Kalloo, "Kale Brassica olaracea L. var. acephala," in Genetic Improvement of Vegetable Crops, G. Kalloo and B. O. Bergh, Eds. Pergamon, 1993, pp. 187-190.

[40] R. Domínguez-Perles, P. Mena, C. García-Viguera, and D. A. Moreno, "Brassica Foods as a Dietary Source of Vitamin C: A Review,” Crit. Rev. Food Sci. Nutr., vol. 54, no. 8, pp. 1076-1091, 2014, doi: 10.1080/10408398.2011.626873.

[41] A. J. Bicksler, "Testing Seed Viability Using Simple Germination Tests," ECHO Asia Notes, no. 11, pp. 4-10, 2011.

[42] B. D. Živanovic, "Chapter 16 Quanti fi cation of the Antioxidant Activity in Salt-Stressed Tissues," vol. 913, pp. 237-250, 2012, doi: 10.1007/978-1-61779-986-0.

[43] J. Pütter, "Peroxidases," Methods Enzym. Anal., pp. 685-690, 1974, doi: 10.1016/b978-0-12-0913022.50033-5.

[44] J. Wilkesman, "Zymography," Methods Mol. Biol., vol. 1626, pp. 25-31, 2017, doi: 10.1007/978-14939-7111-4.

[45] V. Rameeh, M. Niakan, and M. Hossein Mohammadi, "Sulfur effects on sugar content, enzyme activity and seed yield of rapeseed (Brassica napus 1.)," Agron. Colomb., vol. 37, no. 3, pp. 211-216, 2019, doi: 10.15446/agron.colomb.v37n3.71830.

[46] Y. Kono, "Generation of Superoxide Radical during Autoxidation of Hydroxylamine and an Assay for Superoxide Dismutase," vol. 186, no. 1, pp. 189-195, 1978.

[47] L. Flohé and F. Otting, "Superoxide dismutase assays. Oxygen Radicals in Biological Systems," Methods Enzymol., no. 105, pp. 93-104, 1984.

[48] E. El-argawy and I. A. Adss, "Quantitative Gene Expression of Peroxidase , Polyphenoloxidase and Catalase as Molecular Markers for Resistance against Ralstonia solanacearum," no. April, pp. 88-100, 2016.

[49] B. B. Mishra and S. Gautam, "Polyphenol Oxidases : Biochemical and Molecular Characterization , 
Distribution , Role and its Control," vol. 5, no. 1, pp. 1-9, 2016, doi: 10.4172/2329-6674.1000141.

[50] H. Aebi, "Catalase in vitro," Meth. Enzym., vol. 105, no. 1947, pp. 121-126, 1984.

[51] C. Miyake and K. Asada, "Inactivation Mechanism of Ascorbate Peroxidase at Low Concentrations of," vol. 37, no. 4, pp. 423-430, 1996.

[52] Y. Nakano and K. Asada, "Hydrogen Peroxide is Scavenged by Ascorbate-specific Peroxidase in Spinach Chloroplasts," Cell Plant Physiol., vol. 22, no. 5, pp. 867-880, 1981.

[53] H. Meng, S. Hua, I. H. Shamsi, G. Jilani, Y. Li, and L. Jiang, "Cadmium-induced stress on the seed germination and seedling growth of Brassica napus L., and its alleviation through exogenous plant growth regulators," Plant Growth Regul., vol. 58, no. 1, pp. 47-59, 2009, doi: 10.1007/s10725-0089351-y.

[54] P. Taylor, B. M. Shanmugaraj, and H. M. Chandra, "Cadmium Induced Physio-Biochemical and Molecular Response in Brassica Juncea," Int. J. Phytoremediation, vol. 15, no. 13, pp. 206-218, 2013, doi: 10.1080/15226514.2012.687020.

[55] C. Zhang et al., "Resistance of alfalfa and Indian mustard to $\mathrm{Cd}$ and the correlation of plant Cd uptake and soil Cd form," Environ. Sci. Pollut. Res., vol. 26, no. 14, pp. 13804-13811, 2019, doi: 10.1007/s11356-018-3162-0.

[56] M. Mobin and N. A. Khan, "Photosynthetic activity, pigment composition and antioxidative response of two mustard (Brassica juncea) cultivars differing in photosynthetic capacity subjected to cadmium stress," J. Plant Physiol., vol. 164, no. 5, pp. 601-610, 2007, doi: 10.1016/j.jplph.2006.03.003.

[57] Z. Wu et al., "Antioxidant enzyme systems and the ascorbate-glutathione cycle as contributing factors to cadmium accumulation and tolerance in two oilseed rape cultivars (Brassica napus L.) under moderate cadmium stress," Chemosphere, vol. 138, pp. 526-536, 2015, doi: 10.1016/j.chemosphere.2015.06.080.

[58] T. Armas et al., "Comparison of cadmium-induced oxidative stress in Brassica juncea in soil and hydroponic cultures,” pp. 297-305, 2015, doi: 10.1007/s11104-014-2330-3.

[59] D. Kapoor, S. Kaur, and R. Bhardwaj, "Physiological and Biochemical Changes in Brassica juncea Plants under Cd-Induced Stress," Biomed Res. Int., vol. 2014, 2014, doi: 10.1155/2014/726070.

[60] S. Hayat, B. Ali, S. A. Hasan, and A. Ahmad, "Brassinosteroid enhanced the level of antioxidants under cadmium stress in Brassica juncea," vol. 60, pp. 33-41, 2007, doi: 10.1016/j.envexpbot.2006.06.002 